\title{
Helena Guedes
}

\section{Gravidez Real de Maria: uma metodologia para afastar o machismo da fé cristã}

\author{
Embarazo real de María: una metodología para alejar \\ el machismo de la fe cristiana
}

\section{Real Pregnancy of Mary: a methodology expel the "machismo" of the Christian faith}

Resumo: Este artigo aborda o machismo presente na forma como as comunidades cristãs, de modo geral, interpretam a Bíblia, deixando de observar o contexto histórico da época em que Jesus e Maria viveram, ignorando a opressão sofrida por meninas adolescentes, vítimas de estupro e demais tipos de violência, o que pode explicar a concepção real de Jesus, através de um estupro ou de uma conjunção carnal consentida. Busca-se mostrar que as mesmas estruturas de opressão machista ainda se fazem presentes atualmente, prejudicando o pleno desenvolvimento de meninas e meninos. Critica-se a omissão das comunidades cristãs, mantendo-se o pudor e o silêncio que servem de ferramenta para a opressão patriarcal.

Palavras-chave: jovens, Jesus, Maria, sexo, gravidez, estupro, machismo, cristãos

Resumen: Este artículo aborda el machismo presente en la forma en que las comunidades cristianas, en general, interpretan la Biblia, dejando de observar el contexto histórico de la época en que Jesús y María vivieron, ignorando la opresión sufrida por niñas adolescentes, víctimas de violación otros tipos de violencia, lo que puede explicar la concepción real de Jesús, a través de una violación o de una conjunción carnal consentida. Se busca mostrar que las mismas estructuras de opresión machista todavía se hacen presentes actualmente, perjudicando el pleno desarrollo de niñas y niños. Se critica la omisión de las comunidades cristianas, manteniéndose el pudor y el silencio que sirven de herramienta para la opresión patriarcal.

Palabras clave: jóvenes, Jesús, María, sexo, embarazo, estupro, machismo, cristianos 
Abstract: This article discusses the sexism present in the way that christian communities interpret the Bible in general, failing to observe the historical context of the time when Jesus and Mary lived, ignoring the oppression suffered by adolescent girls, victims of rape and other types of violence, which may explain the actual conception of Jesus, through rape or a consensual carnal conjunction. It seeks to show that the same structures of macho oppression are still present today, hampering the full development of girls and boys. The omission of the christian communities is criticized, maintaining the modesty and silence that serve as a tool for patriarchal oppression.

Keywords: youth, Jesus, Mary, sex, pregnancy, rape, machismo, christians

A dúvida mais difícil de esclarecer, na história do cristianismo, é: Maria concebeu Jesus em seu ventre sem relação sexual tal como um acontecimento sobrenatural ou as comunidades cristãs recusam-se a falar de sexo dentro das igrejas a ponto de esconderem a maneira real pela qual Jesus foi gerado?

Ora, se Deus é onipotente, Ele poderia realizar qualquer milagre que desejasse, até mesmo uma gravidez sem conjunção carnal. Sendo Deus um ser extraordinário, é plausível que tenha feito um milagre, trazendo Jesus ao mundo pelo simples recair do Espírito Santo sobre Maria (Lucas 1, 35). E diante dos desígnios de Deus, é inócuo buscar explicações, pois nossa lógica é limitada para tamanha compreensão. É uma conclusão coerente, porém superficial.

Se Jesus veio ao mundo para nos dar seu exemplo e mostrar que não é preciso ser Deus para conseguir suportar todas as injustiças, medos e sofrimentos, sem perder o amor ao próximo, a solidariedade, a paz e a harmonia, sobretudo, sem perder a fé, é mais coerente supor que Deus tenha preferido fazer Jesus nascer, crescer e morrer como qualquer outro ser humano, isto é, de uma maneira real e não mágica.

Em outras palavras, Deus queria nos provar que podíamos realizar sim diversos milagres, mas desde que aprendêssemos a acreditar em nós mesmos, a amarmos uns aos outros incondicionalmente, extirpando de nossos corações o ódio, a inveja, o ciúme e a ganância. Mas para nos convencer, foi preciso trazer à Terra um ser humano que já havia aprendido esta lição. Esse homem, de carne e osso, de virtudes, mas também de fraquezas, foi Jesus de Nazaré.

Se a missão dele era nos encorajar a ter fé, não faz sentido que sua natureza fosse diferente da nossa, isto é, gerado através de uma gravidez não sexualizada, ao contrário do que acontece com todos os animais.

Esta ponderação não deve agradar muitos cristãos. Isso porque, Jesus seria fruto do pecado, um filho bastardo (Mateus, 1,18-19; João, 
8,41). Com efeito, quando Maria engravidou, ela ainda não era casada. Uma mulher solteira, naquela época, deveria se manter virgem até casar-se (Êxodo 22,16 e 1 Tessalonicenses 4, 3). Admitir que ela tenha se relacionado sexualmente com algum homem antes do casamento implica necessariamente reconhecer que Maria teria praticado um ato imoral ou pecaminoso para a época.

Nesse sentido, muitos rejeitam essa tese, pois temem a conclusão de que um filho bastardo não poderia ser o messias prometido, filho de Deus. Trata-se de um pensamento apressado. Existem explicações reais, sem abalar a grandiosidade das figuras de Jesus e de sua mãe.

A primeira pergunta que se faz é: Maria perderia sua pureza e fidelidade a Deus apenas por ter praticado sexo antes do casamento? Isso é pecado aos olhos de Deus? Ora, é certo que a pureza de Maria não pode estar meramente num hímen intacto, mas sim no seu amor verdadeiro a Deus e ao próximo. Logo, o ato sexual, realizado com amor, embora sem atender às expectativas sociais da época, não infringiria as verdadeiras leis de Deus.

Basta imaginar que Maria fosse uma adolescente em 2016, obrigada a casar com um homem que não amasse. Como a maioria das adolescentes, estaria ansiosa por exercer a sua sexualidade, experimentar a beleza e as potências de seu corpo. E, por mais que seus pais lhe impusessem o dever de preservar-se até o dia de subir ao altar para um homem estranho, se sobre ela pairasse uma paixão de arrancar suspiros por aquele que verdadeiramente amasse, o mero arrepio causado pelo sopro de um vento nos pelos do pescoço seria suficiente para impeli-la ao prazer carnal.

Atualmente, é muito comum entre os jovens praticarem sexo independentemente de terem um relacionamento sério e estável. Para muitos desses jovens, o sexo com amor que Deus quer não é aquele praticado após o casal assinar uma certidão de casamento, durante uma festa luxuosa, para satisfazer às expectativas dos pais, do pastor da igreja evangélica ou do padre. Ao contrário, é aquele praticado quando se há carinho, amizade, respeito e companheirismo, não tendo importância a nomenclatura que a sociedade confere ao tipo de relacionamento: casamento, noivado, namoro, romance ou apenas um "lance", expressão usualmente empregada pelos jovens para se referir a um relacionamento sem compromisso ${ }^{1}$.

Disponível em: < https://br.answers.yahoo.com/question/index?qid=20110709094941AAwi5XJ >. Acesso em: 21 de nov. de 2016. 
Ao que parece, as novas juventudes reconhecem a diferença entre um relacionamento vulgar de um relacionamento de amor, ainda que fluido. É o que se pode observar da canção de funk chamada "Um pente é um pente" ${ }^{2}$, criada pelo grupo Os Hawaianos. A canção distingue o sexo destinado à mera satisfação carnal (o "pente") de outras formas de relação, com envolvimento amoroso, porém sem comprometimento (o lance ou o romance).

O nome foi extraído do modo acelerado como o pente - carregador de armas de fogo modernas - permite a recarga de munições. À semelhança do pente que realiza o disparo de um projétil logo após o outro, o sexo também seria feito, nesse caso, com uma pessoa logo após a outra ${ }^{3}$.

Então, na hipótese de Maria estar sendo obrigada pela família a se casar com José, impedida de casar com o seu verdadeiro amor e exercer sua própria vontade, que pecado lhe poderia ser imputado por se rebelar contra essa imposição patriarcal? Nenhum! As regras morais e religiosas é que são pecaminosas quando se afastam da única regra sagrada que é amar uns aos outros como a si mesmo e amar a Deus sobre todas as coisas. Elas devem se prestar à felicidade humana. Do contrário, devemos nos desapegar delas e modificá-las.

Mais que uma mera imposição, o que Maria sofria, assim como as demais mulheres de sua época, chama-se opressão. Não se podem olvidar as condições sociais a que elas estavam submetidas naquela sociedade patriarcal. Meninas e mulheres não dispunham de qualquer autonomia, pois sua vontade não era levada em consideração. Era o patriarca quem decidia se casariam, quando e com quem. Elas não escolhiam se queriam ter filhos ou mesmo se queriam ter relações sexuais. Eram meros objetos. Não possuíam nome próprio, pois eram identificadas como propriedade de seu pai, irmão ou marido. A elas cabia unicamente realizar trabalho doméstico. 0 casamento era mais um instrumento de aliança política e troca de patrimônio entre as famílias do que uma união afetiva ${ }^{4}$. Um homem que fosse flagrado conversando com uma mulher seria considerado um tolo, pois elas eram vistas como burras, ignorantes e até mesmo perigosas ${ }^{5}$.

\footnotetext{
2 Disponível em: <https://www.vagalume.com.br/os-hawaianos/um-pente-e-pente.html>. Acesso em: 2 de nov. de 2016.

3 Disponível em: <https://br.answers.yahoo.com/question/index?qid=20100216153426AAeJZ DN>. Acesso em: 2 de nov. de 2016.

4 Disponível em:<http://www.egov.ufsc.br/portal/conteudo/evolu\%C3\%A7\%C3\%A3ohist $\%$ C3\%B3rica-e-legislativa-da-fam\%C3\%ADlia-e-da-filia\%C3\%A7\%C3\%A3o>. Acesso em: 6 de nov. de 2016.

5 Disponível em:<http://www.abiblia.org/ver.php?id=6224>. Acesso em: 2 de nov. de 2016.
} 
Por que perigosas? Será mesmo que homens, fisicamente mais fortes, sentiriam medo de uma mulher? Medo do seu fantasioso poder de sedução? Certamente que não. 0 perigo tinha origem num preconceito.

O corpo da mulher representava um perigo porque constantemente estava pecaminoso, segundo as leis judaicas do puro e do impuro (Levítico, 12, 1-8; 15, 19-30). Essas leis diziam que qualquer sangramento que ela apresentasse, como no parto ou na menstruação, tornava-a impura e isso significava estar doente (em pecado) e sofrer inúmeras restrições em seu cotidiano. Elas não podiam ser tocadas por seus maridos, sob pena de eles se tornarem impuros também (Levítico, 15, 24). Elas não podiam encostar em nenhum objeto sagrado. Não podiam entrar em templos religiosos enquanto não se submetessem ao ritual de purificação (Levítico, 12, 4) .

O indivíduo temia morrer da sua impureza e, por isso, precisava se deslocar até o templo para sacrificar um animal, em oferenda (Levítico, $12,6 ; 15,29)$ como forma de resgatar sua saúde. A prática era realizada com muita frequência, já que eram muitas as causas de impureza. Além das despesas de deslocamento até o templo, adquirir um bezerro ou cordeiro especial para o abate seria um grande ônus, sobretudo para o povo escravizado. 0 sacrifício era exigido até mesmo dos mais pobres, pois se admitia a substituição de um cordeiro por pombinhos (Levítico, 12,8), tirando deles a única refeição.

0 medo que as pessoas sentiam dos impuros não consistia apenas no receio de se contaminarem. Temiam a miséria por não poder trabalhar no período da impureza, mas, sobretudo, temiam o preconceito, pois seriam mal vistas pela comunidade e, até mesmo, podiam ser condenadas ao isolamento, como ocorria com os leprosos (Levítico 13, 45-46).

Nesse contexto, é possível imaginar que os homens deveriam permanecer em constante vigília ao se aproximarem de uma mulher, evitando qualquer contato. Na dúvida, sem saber se elas estavam ou não no período menstrual, o corpo da mulher representava uma constante ameaça.

Por outro lado, essa prática era muito rentável para o templo, pois as ofertas oriundas dos sacrifícios eram fonte de farta arrecadação para os sacerdotes (SOUZA, 2013). 0 templo foi se transformando em centro de comércio, especialmente dos próprios animais sacrificados - não é à toa que Jesus, posteriormente, irá expulsar os vendilhões, justamente para combater a exploração dos mais pobres (João, 2, 14-16). 
Observa-se que essas leis que, inicialmente serviam para manter a união e a identidade do povo judeu, com o passar do tempo, foram se tornando o fundamento para legitimar a opressão da elite judaica e romana sobre o povo sofrido e carente (SOUZA, 2013). Ou seja, as práticas sociais passaram a estar mais voltadas à estrita observância das leis do que à realização do bem comum. Isto é, o respeito às leis sagradas não se prestava mais à felicidade humana e o povo oprimido não percebia que era hora de mudar suas leis.

No caso das mulheres, além da opressão financeira pela exploração religiosa, elas sofriam exploração ainda mais grave e perversa, por parte do preconceito de gênero. 0 medo que seu corpo ensejava servia de fundamento para mantê-la sob controle.

Nesse sentido, se Jesus é fruto de um amor proibido, que Maria viveu por ter transgredido a opressão, isso apenas confirma sua grandiosidade. A busca por seu verdadeiro amor revela força, coragem, amor e confiança em si mesma. Ela se permitiu ser feliz. Romper uma tradição milenar é tarefa extremamente sofrível, como até hoje é, afinal as pessoas não costumam repensar facilmente sua moral. Basta lembrar dos homossexuais e transexuais que, ainda em 2016, são bastante discriminados por desobedecerem o padrão de comportamento imposto pela heteronormatividade.

Mesmo assim, vale a pena insistir nessa ruptura de valores quando se está em jogo a liberdade de amar. É esse lado da possível história de Maria que foi desprezado pelas igrejas. É preciso trazer à consciência dos cristãos que Maria lutou pelo fim da subjugação da mulher. Vale dizer, falar da sua gravidez real simboliza hoje um grito de liberdade e independência contra o machismo que ainda está impregnado na cristandade.

Mas a investigação não acaba aqui. Nos anos anteriores ao nascimento de Jesus, o povo judeu vinha sofrendo grande dominação pelo Império Romano. A Palestina estava sob o governo do Imperador $\mathrm{Au}-$ gusto (30 a.C. - 14 d.C.), sendo que seu território era dividido em regiões (Galiléia, Judéia, Samaria, Peréia etc.) dominadas por governantes regionais, chamados de tetrarcas. 0 tetrarca que comandava a região da Galiléia era Herodes Antipas (FRÖHLICH, 1987).

Maria vivia na cidade de Nazaré, na região da Galiléia (Lucas, 2, 4). Nazaré era um vilarejo muito pobre como os demais daquela região ao norte da Palestina. Localizava-se longe do comércio, do templo, da sede do governo romano e do povo judeu mais rico, elitizado e fiel aos 
costumes religiosos, como os fariseus e saduceus, porque o povo mais rico se concentrava na capital, Jerusalém, na Judéia. Apesar da distância e da pobreza, os soldados romanos se faziam presentes em Nazaré para a cobrança dos impostos que sustentavam o tetrarca. E, para alcançar este fim, impunham violentos castigos, humilhações e ameaças.

A Galiléia situava-se próxima da fronteira com outras nações, como a Fenícia e a Síria. Por isso, os galileus incorporavam em seu comportamento alguns hábitos da cultura estrangeira (pagã), o que os distinguia dos fariseus, da Judéia, que cumpriam as leis sagradas com bastante rigor. Assim, os fariseus discriminavam os galileus, pois não viam com bons olhos a cultura pagã politeísta. Os galileus eram discriminados até mesmo pelo seu linguajar que denunciava de onde vinham (Mateus, 23, 73). Falava-se em Galiléia dos gentios (Isaías 9, 1) ou Galiléia das nações (Mateus, 4,15$)^{6}$. Os fariseus acreditavam que da Galiléia nenhum profeta poderia surgir (João 7, 52).

Em resumo, um galileu era visto pelos judeus mais ricos como pessoas pobres, doentes, impuras, violentas (Lucas 13,1-2) e desrespeitadoras das leis judaicas por se promiscuírem com os gentios e, por isso mesmo, julgavam-nos merecedores da miséria e da exploração.

Não parece uma realidade muito diferente da de muitos negros e negras, moradores de bairros da periferia da cidade do Rio de Janeiro. É muito comum que pessoas brancas, de classe social rica ou média, especialmente nos bairros nobres da cidade, como Leblon e Ipanema, sintam medo de serem assaltadas quando estão num ônibus e entra um jovem negro pobre e de periferia. São considerados sem educação, violentos, suspeitos de algum crime, mesmo que inexistente, apenas pelo modo de falar, de se vestir, pela cor da pele, pelo estilo de música que escutam e por serem pobres ${ }^{7}$.

Sofrem pelo tratamento discriminatório por parte dos mais ricos, da força policial, comandada por pessoas também ricas, brancas e moradoras de bairros nobres que integram os altos cargos do governo. Sofrem em filas de hospitais públicos, aguardando atendimento médico; sofrem por não terem emprego digno próximo às suas moradias e se veem obrigados a dormir nas ruas para economizar o dinheiro da

6 Disponível em: <http://www.rudecruz.com/a-galileia.php>. Acesso em: 2 de nov. de 2016.

7 Disponível em:

<http://proex.pucminas.br/sociedadeinclusiva/Vseminario/Anais_V_Seminario/direitos/ comu/A\%20DISCRIMINACAO\%20RACIAL\%20NO\%20BRASIL\%20-\%20VERDADES\%20E\%20 MITOS.pdf >. Acesso em: 21 de nov. de 2016. 
passagem de ônibus ou trem. Sofrem pelo tratamento bruto que lhes é dado pelos agentes públicos quando são removidos das ruas para abrigos públicos, sem o respeito à sua dignidade ${ }^{8}$.

À semelhança das mulheres pobres, moradoras de periferia, especialmente negras - que hoje sofrem não só a injustiça de classe, vividas pelos homens pobres, mas também a injustiça de gênero - naquela época, uma mulher galileia sofria a discriminação romana (pela cobrança de impostos e violência dos soldados), religiosa (pela exploração dos fariseus e saduceus) e de gênero, pois até mesmo o galileu pobre e oprimido era opressor frente às mulheres de sua família e comunidade.

Uma estrutura social que não reconhecia na mulher um ser autônomo, capaz de responder por suas próprias vontades, jamais poderia respeitar integralmente sua dignidade, como sujeito de direitos, detentora do livre arbítrio. Ela era meramente um corpo destinado ao trabalho doméstico, à procriação e à satisfação sexual alheia.

Em suma, a sociedade dava pouca ou nenhuma importância ao consentimento da mulher. Essa visão machista impregnou a religião, as leis, a cultura judaico-cristã e se faz presente até mesmo na forma como hoje interpretamos ou deixamos de interpretar a Bíblia.

Será que alguém percebeu que no momento em que o anjo anuncia à Maria que ela conceberá e dará à luz um filho, em momento algum é perguntado a ela se desejava engravidar? É o que se lê no primeiro capítulo do Evangelho de Lucas:

\footnotetext{
${ }^{26}$ No sexto mês Deus enviou o anjo Gabriel a Nazaré, cidade da Galileia, ${ }^{27}$ a uma virgem prometida em casamento a certo homem chamado José, descendente de Davi. 0 nome da virgem era Maria. ${ }^{28} \mathrm{O}$ anjo, aproximando-se dela, disse: "Alegre-se, agraciada! O Senhor está com você!" ${ }^{29}$ Maria ficou perturbada com essas palavras, pensando no que poderia significar esta saudação. ${ }^{30}$ Mas o anjo lhe disse: "Não tenha medo, Maria; você foi agraciada por Deus! ${ }^{31}$ Você ficará grávida e dará à luz um filho, e lhe porá o nome de Jesus. ${ }^{32}$ Ele será grande e será chamado Filho do Altíssimo. O Senhor Deus lhe dará o trono de seu pai Davi, ${ }^{33}$ e ele reinará para sempre sobre o povo de Jacó; seu Reino jamais terá fim". ${ }^{34}$ Perguntou Maria ao anjo: “Como acontecerá isso se sou virgem?" 350 anjo respondeu: "O Espírito Santo virá sobre você, e o poder do Altíssimo a cobrirá com a sua sombra. Assim, aquele que há de nascer será chamado Santo, Filho de Deus. (...) ${ }^{37}$ Pois nada é impossível para Deus". ${ }^{38}$ Respondeu Maria: "Sou serva do Senhor; que aconteça comigo conforme a tua palavra". Então o anjo a deixou. (LUCAS, 1, 26-38) Sem grifos no original.
}

\footnotetext{
8 Disponível em: <http://piaui.folha.uol.com.br/materia/morar-na-rua-em-ipanema/>. Acesso em: 6 de nov. de 2016.
} 
A resposta de Maria, ao final, não supre a ausência de seu consentimento. Porque o anjo sentencia o seu futuro, não deixando qualquer margem de escolha para ela, a não ser obedecer, como comumente cabia às mulheres diante das decisões do seu marido ou de seu pai.

Os homens que escreveram a Bíblia devem ter sido machistas, mas certamente os anjos enviados de Deus jamais o seriam. Este diálogo não deve ter acontecido dessa maneira, a menos que até Deus seja machista. Nesse caso, melhor falar em deus. Porque Deus não pode querer um mundo em que a vontade da mulher seja desprezada tampouco desrespeitada. 0 nome que se dá a uma gravidez sem consentimento é estupro.

Falando em estupro, chegamos ao ponto nevrálgico da cultura machista. Isso porque, no estupro, o sexo torna-se a ferramenta para a violência. Quando o homem descobriu que sua genitália poderia servir como arma para provocar medo, passou a usar o sexo como mecanismo de dominação das mulheres, crianças e, até mesmo, de outros homens (LARA, B., 2016).

Nesse sentido, o estupro foi erigido à categoria de tática de guerra. São frequentes os exemplos de estupros coletivos na história. É o caso da Segunda Grande Guerra, em que se estima que cerca de $100 \mathrm{mil}$ mulheres tenham sido estupradas pelos exércitos soviético, americano e francês apenas em Berlim e 2 milhões no território alemão; recentemente, tivemos o caso do grupo terrorista Boko Haram que sequestrou, pelo menos, 2 mil mulheres e meninas para serem usadas e vendidas como escravas sexuais (LARA, B., 2016).

Não se deve esquecer que o estupro não era/é considerado uma ofensa à pessoa da mulher, mas sim à sua família, isto é, era uma forma de destruir o clã ao qual ela pertencia. Não sendo a mulher uma pessoa em si mesma, mas apenas um objeto, a violência contra ela retirava do patriarca a possibilidade de usá-la em alianças com outras famílias, por meio do matrimônio. Porque seu valor de troca era a virgindade (LARA, B., 2016).

Recentemente, foi noticiado pelos diversos jornais um estupro coletivo possivelmente praticado por 33 jovens contra uma menina de 16 anos de idade, dentro de uma favela no bairro de Santa Cruz, Zona Oeste do Rio de Janeiro. Os suspeitos somente puderam ser investigados porque um deles disponibilizou nas redes sociais um vídeo, mostrando imagens da vítima seminua e sangrando, vangloriando-se pelo intento ${ }^{9}$.

Disponível em: < http://g1.globo.com/rio-de-janeiro/noticia/2016/05/jovem-que-teria-sidovitima-de-estupro-coletivo-faz-exames-no-rio.html > . Acesso em: 8 de nov. de 2016. 
Nos dias seguintes, circulavam pela internet inúmeras mensagens para difamar a reputação da menina, dizendo que ela gostava de ir a bailes funks na favela e criticando-a por não ter denunciado o crime imediatamente, como se esses argumentos levassem à conclusão de que ela teria participado de um bacanal e, por isso, mereceria tal sofrimento ${ }^{10}$.

Quer dizer, um número expressivo de pessoas ignora que sexo sem consentimento da mulher é crime, seja quem for essa mulher, e ainda usa a sua desmoralização para inocentar não os suspeitos, mas sim seus próprios machismos.

Esse crime pérfido e a reação das pessoas que tentaram naturalizá-lo somente podem ser explicados à luz de uma cultura de estupro: um conjunto de ideias e comportamentos, ainda que não conscientes, que esconde ou nega a violência sexual contra meninas e mulheres ${ }^{11}$.

Parte dessa cultura tem origem na recusa das igrejas e lideranças cristãs em tratar do tema sexo, de uma maneira aberta e responsável, sem hipocrisia ou tabus, voltando-se especialmente para os jovens, adolescentes e até crianças. De modo geral, a cristandade tem se omitido diante do machismo presente em nossa cultura, até mesmo na forma como se interpreta a Bíblia. São raros os pastores ou padres que em suas pregações ou homilias enfatizem o fato de, por exemplo, no evangelho de Lucas, não constar que o anjo tenha pedido o consentimento de Maria para sua gravidez. Nos casamentos religiosos, é comum afirmarem que a mulher deve obedecer aos maridos porque está escrito na Bíblia que ele é a cabeça da mulher (Efésios 5, 23-24), optando por uma interpretação acrítica e descontextualizada ${ }^{12}$.

Outro exemplo machista que é invisibilizado pela maioria dos religiosos está no Antigo Testamento: a vida da mulher estuprada sequer merecia proteção se ela não gritasse por socorro (Deuteronômio 22, 23-24). Por certo, presumia-se que, se a vítima não bradasse, estaria aceitando a relação sexual e, por isso, mereceria o mesmo castigo que seu algoz. Essa lei de deus ignorava absolutamente qualquer outra justificativa para o seu silêncio, como o medo da morte, o pudor pela humilhação, porque a sociedade que a elaborou em nome de Deus desprezava a vontade da mulher.

10 Disponível em: < http://jconline.ne10.uol.com.br/canal/mundo/brasil/noticia/2016/05/27/ vitima-de-estupro-por-33-homens-garota-tem-vida-exposta-na-internet-237715.php > . Acesso em: 8 de nov. de 2016.

11 Disponível em: < http://guiadoestudante.abril.com.br/blogs/atualidades-vestibular/o-que-ecultura-do-estupro/ >. Acesso em: 8 de nov. de 2016.

12 Disponível em: < http://www.ipsantoamaro.com.br/ump/blog-da-ump/o-papel-da-esposa-edo-marido-no-casamento.html >. Acesso em: 21 de nov. de 2016. 
Da mesma forma, a sociedade carioca presumiu que, se aquela menina gostava de frequentar bailes funks ou se não denunciou à polícia, ela, então, não seria vítima, mas sim uma mentirosa e promíscua. Porque vivemos em um mundo em que a vontade da mulher, sobretudo jovens, continua sendo ignorada, a ponto de acreditarmos que estupro se confunde com sexo na modalidade pente.

Esse quadro muda pouco quando analisamos as leis brasileiras. O nosso Código Penal, editado em 1940, previa, até 2009, o crime de estupro no capítulo sobre os crimes contra os costumes (e não contra a dignidade sexual). Além disso, a lei descrevia a vítima como mulher honesta para excluir da proteção aquelas que fossem prostitutas ou promíscuas ${ }^{13}$.

Ora, se mesmo em 2016 a sociedade banaliza um crime de estupro, dependendo de quem é a mulher, o que pensariam homens há dois mil anos em relação à súbita gravidez de uma jovem, paupérrima, de linguajar pagão, moradora da Galiléia, como foi Maria?

As meninas judias deveriam ser frequentemente vítimas de estupro por soldados romanos, quando as tropas de Herodes Antipas invadiam a cidade de Nazaré. Além de agredidas e humilhadas, precisavam esconder de todos a violência sofrida, por causa do prejuízo que o defloramento ensejava ao patriarca. E pior: elas temiam ser mortas caso não provassem ter gritado por socorro durante o ato sexual.

Nesse sentido, é razoável que Maria tenha sido estuprada. Esta é a tese defendida pelo cineasta holandês Paul Verhoeven ${ }^{14}$ para negar que Jesus seja filho de Deus e, por isso, vem sofrendo severas críticas da comunidade cristã que não admite que a gravidez de Maria possa provir de uma conjunção carnal ${ }^{15}$.

A tese do autor holandês é plausível, muito embora sua conclusão possa não ser correta. 0 fato de Jesus ter um pai biológico, ainda que seja um agressor, não nega que Ele seja o messias prometido. Ao contrário, a história real de Jesus revela, com ainda maior evidência, sua divindade, pois é prova viva de que o amor mais sublime pode nascer da violência mais cruel. Assim como os filhos aprendem com suas mães

13 Disponível em: < http://www.planalto.gov.br/ccivil_03/decreto-lei/Del2848.htm >. Acesso em: 6 de nov. de 2016.

14 Disponível em: < http://www.socialistamorena.com.br/10-versoes-hereges-para-jesusliberdade-de-pensamento-e-a-neo-inquisicao-virtual/ > . Acesso em: 6 de nov. de 2016.

15 Disponível em: < http://blogs.odiario.com/inforgospel/2012/09/02/filme-blasfemo-jesus-ofnazareth-diz-que-jesus-foi-fruto-de-estupro-campanha-contra-assine/ > . Acesso em: 8 de nov. de 2016. 
o que é amor, justiça e perdão, Jesus pôde aprender com Maria a dor real que uma mulher vive por ser discriminada, além da dor por ser vítima da violência sexual. Para Jesus ter conseguido se conscientizar de todas as formas implícitas e explícitas de machismo nas leis ditas sagradas, nos costumes e na moral da época, ele certamente sofreu toda essa dor por que sua mãe passou. Por isso, ambos lutaram contra a opressão.

Uma das provas de que Jesus foi feminista está em ele desobedecer às leis da pureza. Ao ser tocado por uma mulher que sangrava, Ele não sentiu medo tampouco ordenou a moça ir até o templo comprar um cordeiro para dar em oferenda. Apenas a consolou e lhe aconselhou seguir em paz, ignorando aquela lei opressora (Marcos 5, 25-34).

O que se observa, nesse contexto, é que a comunidade cristã, de modo geral, recusa-se a trazer para dentro das igrejas o debate sobre sexo porque não quer combater a estrutura social patriarcal e a ideologia machista que tem sido a causa de tantas mazelas para mulheres, meninas e crianças. Os cristãos, com poucas exceções, têm deixado de denunciar que a cultura machista, na qual se insere a cultura do estupro, explica porque um em cada três homens, no Brasil, culpam a mulher em caso de estupro ${ }^{16}$, e ainda, porque, em média, no Brasil, 13 mulheres são assassinadas por dia $^{17}$, sendo que $50,3 \%$ desses homicídios são cometidos por familiares ${ }^{18}$.

Muitos tentam desmoralizar a crítica ao machismo estrutural, denominando-o de "ideologia de gênero". Não é à toa que leis pouco democráticas ${ }^{19}$ estão sendo formuladas para impedir que escolas estimulem seus alunos a desenvolver o pensamento crítico, porque o preconceito tem sido introjetado na cultura popular como sendo a vontade de Deus.

Seriam incomensuráveis os benefícios que traríamos para nossa sociedade se meninas e meninos pudessem falar abertamente, sem culpa e sem repressão, sobre seus sentimentos e desejos carnais dentro das igrejas, mesmo porque a repressão sexual que os adultos possam

\footnotetext{
16 Disponível em: < http://g1.globo.com/sao-paulo/noticia/2016/09/um-em-cada-3-brasileirosculpa-vitima-em-casos-de-estupro-diz-datafolha.html >. Acesso em: 8 de nov. de 2016.

17 Disponível em: < http://g1.globo.com/bom-dia-brasil/noticia/2015/11/estudo-diz-que-brasiltem-em-media-13-mulheres-assassinadas-por-dia.html >. Acesso em: 8 de nov. de 2016.

18 Disponível em: < http://g1.globo.com/politica/noticia/2015/11/503-dos-homicidios-demulheres-no-brasil-sao-cometidos-por-familiares.html >. Acesso em: 8 de nov. de 2016.

19 Disponível em: < http://www.brasil247.com/pt/colunistas/durvalangelo/247057/EscolaSem-Partido-a-lei-da-morda\%C3\%A7a.htm >. Acesso em: 8 de nov. de 2016.
} 
impingir a eles não lhes retira os impulsos carnais, apenas conduz a que eles não se compreendam e cresçam insatisfeitos, rebeldes e depressivos. Aceitando este desafio, as comunidades cristãs teriam melhores condições de orientá-los para evitarem gravidez precoce, doenças venéreas, baixa autoestima, que muitas vezes é a causa do sexo vulgar, do ciúme, da violência doméstica e sexual.

Portanto, o que se pretende ao estudar e analisar as possíveis causas para a gravidez de Maria não é desmoralizá-la, desrespeitá-la ou negar a grandiosidade de sua vida e devoção a Deus. Pelo contrário, busca-se aprofundar a fé cristã e aproximá-la da verdadeira moral que Jesus e Maria quiseram nos deixar. Pretende-se promover diálogos constantes e íntimos entre adultos e jovens ou criança, dentro ou fora das igrejas, que quase nunca existiram porque estamos todos inseridos numa cultura de opressão que tem como principais sustentáculos a omissão, o silêncio, o tabu e o pudor. Esse método certamente é incômodo porque nos obriga a desprendermos de certezas ideológicas que estão amparadas em dogmas, preconceitos, tradições milenares. Porém, é o melhor caminho de que dispomos para alcançar a verdadeira essência da trajetória de vida e do pensamento de Jesus. Porque amar é uma tarefa que se conquista através da luta contra todas as injustiças, sobretudo as injustiças na seara do pensamento.

\section{Referências Bibliográficas.}

BOHN GASS, I. Coleção: Uma Introdução à Bíblia. 2ª Ed. São Paulo. Editora Paulus. 2002.

DE LARA, B. et all. \#Meu amigo secreto: feminismo além das redes. Rio de Janeiro. Edições de Janeiro. 2016.

DE SOUZA LINO, M. Quando o leão ruge...: o verdadeiro jejum que agrada a Deus. Campos do Jordão. Clube dos Autores. 2013.

FRÖHLICH, R. Curso Básico de História da Igreja. São Paulo. Editora Paulus. 1987.

Sobre a autora, Helena Guedes Freitas: formada em Ciências Jurídicas e Sociais pela Faculdade Nacional de Direito da Universidade Federal do Rio de Janeiro, pós-graduanda pela Escola da Magistratura do Estado do Rio de Janeiro. Trabalha atualmente como assessora jurídica no Tribunal de Justiça do Estado do Rio de Janeiro. Membro da Secretaria de Publicidade do Centro de Estudos Bíblicos no Rio de Janeiro e da Secretaria de Publicidade do Centro de Estudos Bíblicos em Campo Grande, Rio de Janeiro. 